\title{
Preparation and Processing Of Orange Flavoured Aloevera Gel
}

\author{
Sameer Maqbool ${ }^{1,}$ Dr. Deeba S Jairajpuri ${ }^{2,}$ Khalid Bashir $^{3}$ \\ ${ }^{1,2,3}$ Department of Food Technology Faculty of Engineering and Interdisciplinary Sciences (FEIS) Jamia \\ Hamdard, Hamdard University, New Delhi-62
}

\begin{abstract}
Aloe Vera has gained more attention over the last decade due to its reputable, medicinal, and pharmaceutical and food properties. In present research, firstly the different concentrations of pectin and gum acacia were augmented with aloevera gel and the products so prepared were assessed for texture and stickiness. The selected preparation was then supplemented with orange flavour at different levels. The samples were again analysed for taste, color and stickiness and the final product so prepared was subjected to various nutritional, organoleptic and microbial analysis. On the basis of sensory characteristics and nutritional value, Aloe vera gel when added with $1.5 \%$ pectin, $9 \%$ gum acacia and $15 \mathrm{~g}$ orange flavour resulted in better quality gel with smooth texture, acceptable appearance and aroma and attractive colour and good nutritional value (protein content $4 \%$, carbohydrate content $18.6 \%$, TSS $41.7^{\circ}$ B, fibre content $2.83 \%$ and mineral content $1.29 \%$ ).
\end{abstract}

Keywords: Aloe vera gel, flavour, pectin, gum acacia.

\section{Introduction}

Aloe vera is a neutraceutical having loads of nutrients has a beneficial effect on human health and can cure many diseases. Aloe vera boosts immune function and destroys tumours (L. Ralamboranto1982). Galal et al, 1975 studied the effect of Aloe vera gel on ease of inflammation of joints. They suggested it not only reduces inflammation but also reduces arthritis pain when used topically. It was also suggested when used internally, reduced inflammation throughout the body from the inside out. People who drink aloe vera for two weeks typically begin to experience a significant reduction of inflammation symptoms. Aloe Vera gel when used internally, it improves the quality of the blood and helps rebalance the blood chemistry in a way that lowers cholesterol and total triglycerides, in people with elevated levels (Joshi and Dixit, 1986).

Imanishi et al, 1981, Suzuki, 1979 reported that polysaccharides in the aloe vera plant have curative effects on numerous digestive disorders like IBS, ulcers, Crohn's disease. Sai Lakshmi et al., 2011 studied the impact of Aloe vera based antimicrobial coating on storage life of papaya; the typical polysaccharides of Aloe vera possess antifungal activity. ZhanHai Yu et al. 2009 studied the effect of Aloe vera polysaccharides on immunity and antioxidant activities in oral ulcer animal models. The results showed that A. vera polysaccharides enhanced immunity activity and exerted antioxidant effects compared with vehicle controls. These results demonstrate, for the first time, that A. Vera polysaccharides are effective in enhancing innate immunity and suppressing oxidative injury in oral ulcer animals.Compounds extracted from Aloe vera have been used as an immunostimulant that aids in fighting cancers in cats and dogs (King et al., 1995). Aloe vera emodin, an anthraquinone, has the ability to suppress or inhibit the growth of malignant cancer cells making it to have antineoplastic properties (Thomson, 2004). Qian He et al. 2005, developed an ISO9000: 2000 and safety (HACCP) management systems for the food industry to ensure the biological integrity, the organoleptic stability, and the quality of the Aloe vera juice.

D. Jasso de Rodríguez et al . 2005 studied the antifungal activity in vitro of Aloe vera pulp and liquid fraction against plant pathogenic fungi. The Aloe vera leaves were cut from plants grown under greenhouse conditions at the University Antonio Narro, disinfected with sodium hypochlorite, and separated in two groups. In the first group, the pulp was manually scraped out; in the second, a laboratory roll processor was used for the pulp and liquid fraction separation. Both types of extracts were pasteurized. Antifungal activity of pulp and liquid fraction was evaluated on the mycellium development of Rhizoctoniasolani, Fusariumoxysporum, and Colletotrichumcoccodes that were isolated from a potato crop by the hyphae point and monosporic techniques. The results showed an inhibitory effect of the pulp of A. Vera on F. oxysporum at $104 \mu 11^{-1}$ and over a long period.

Keeping in view the nutritive and health benefits of Aloe vera, the present investigation was aimed to produce orange flavoured gel, as it possess bland taste and also Aloe vera gel is not available in the market. Aloe vera gel can serve as the best functional food because of ever responsiveness in consumers towards their health and quality, moreover can meet the demands made by Vegetarians. Besides providing health benefits Aloe vera also have provision for nutrition supplement that can be consumed by every age group. 


\section{Materials and Methods}

The raw materials Aloe vera was obtained from Herbal Garden, Jamia Hamdard University, New Delhi, while pectin (Siscoresh. Lab Pvt.), gum acacia, citric acid (S d fine-chemicals), sodium benzoate, potassium sorbate (Thomas Baker) and orange flavour (International flavour and color fragrance Pvt Ltd) were obtained from the local market.

Sample preparation Process optimization was done by preparing four samples of Aloe vera, $100 \mathrm{~g}$ each and were augmented with pectin and gum acacia at the rate of $(1 \mathrm{~g}, 5 \mathrm{~g}),(1.25 \mathrm{~g}, 7 \mathrm{~g}),(1.5 \mathrm{~g}, 9 \mathrm{~g})$ and $(1.75 \mathrm{~g}, 11 \mathrm{~g})$ respectively. Then all the samples were assessed for texture and stickiness. The sample 3 (containing pectin $1.5 \mathrm{~g}$ and gum $9 \mathrm{~g}$ ) was selectedand then supplemented with orange flavour at $5 \mathrm{~g}, 10 \mathrm{~g}, 15 \mathrm{~g}$ and $20 \mathrm{~g}$ levels. These flavoured samples were again analysed for taste, color and stickiness and the final product selected contained $15 \mathrm{~g}$ orange flavour was subjected to various nutritional, organoleptic and microbial analysis.

Physio-chemical characteristicsMoisture, ash and fat content were determined according to AOAC 2000 methods. Protein content was determined as per (IS: 7219:1973): Kjeldhal Method, protein content was obtained by using the conversion factor of 6.25 , Crude fibre was determined by (IS: 11062) and carbohydrate content by difference method. TSS was determined by refractometer, $\mathrm{pH}$ by $\mathrm{pH}$ meter (Toshcon instruments).

Gel PreparationThe Aloe vera leaves were harvested from the Herbal Garden field and then taken to the processing place. The leaves were then washed by tap water followed by chlorine wash and then again by fresh water. The leaves were then kept in upright position for $15 \mathrm{~min}$ in a bowl to remove some of the yellowish fluid coming from skin. The head portion was removed and the leaves were then cut in the middle lengthwise and the gel was obtained. The gel was obtained gently without contaminating it with sap of the skin.

The gel was then subjected to grinding (Usha Grinder) at room temperature for $10 \mathrm{~min}$ only to avoid browning. Then filtration was done by allowing it to pass through carbon coated plates and muslin cloth (to remove alion and alieemodin present in peels not in gel). Citric acid was then added to the gel in order to stabilize it and stop browning and the $\mathrm{pH}$ was adjusted to 3 to 3.5. Gel was then pasteurised at $89{ }^{\circ} \mathrm{C}$ for $1-2$ min and then immediate cooling to $5{ }^{\circ} \mathrm{C}$. after pasteurisation the other ingredients like orange color, preservatives (sodium benzoate, potassium sorbate), sugar $(7 \mathrm{~g})$, pectin and gum acacia was added. The gel was then again mixed thoroughly for $3 \mathrm{~min}$.Gel so prepared was then transferred to air tight bottles and stored under refrigerated conditions for further nutritional analysis.

Microbial analysis Yeast, mold and Salmonella growth was checked. Analysis at different intervals of time was done at different temperatures for example; for yeasts and molds at $28^{\circ} \mathrm{C}$, for salmonella at $36^{\circ} \mathrm{C}$.

Sensory evaluation Gel was evaluated for overall acceptability (colour, texture, aroma, stickiness and taste) and was carried out as per 9 point Hedonic scale, by the help of ten semi trained judges.

\section{Results and Discussion}

Proximate composition of Aloe vera gelThe nutritional value of the processed and flavoured gel was found within acceptable limits. The carbohydrate content was slightly increased due to added sugar, Table 1 .

Microbial AnalysisNo growth of yeasts, molds and salmonella was found in any of the samples of processed Aloevera gel.

The Sensory evaluation was carried out as per 9 point Hedonic scale, Table 3. The sensory attributes that were taken into consideration include: color, texture, aroma, taste, stickiness, overall acceptability and rank. The values are the means of ten readings.

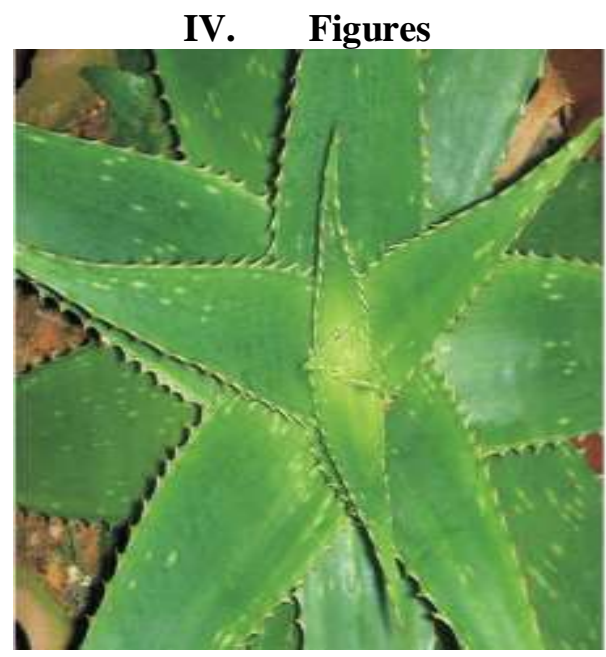

Fig. 1: Aloe vera plant 


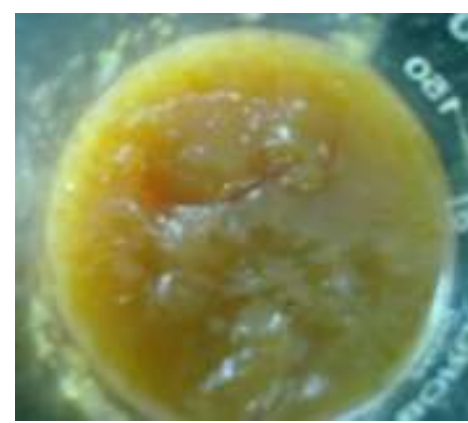

Fig. 2: Aloe vera gel (Top view).

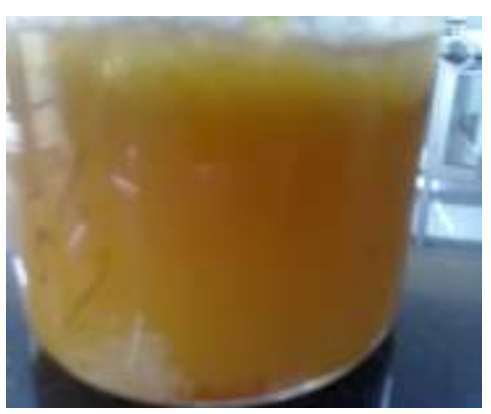

Fig. 3: Aloe vera gel (side view).

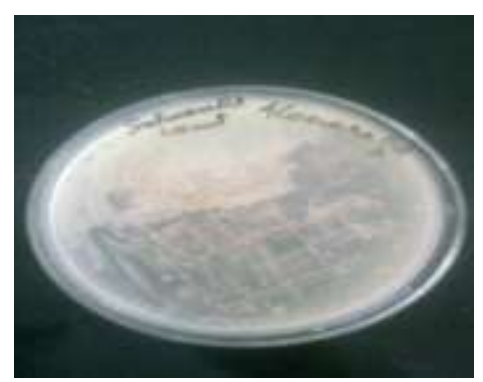

Fig. 4: Gel kept for Salmonella growth

V. Tables

Table 1: Proximate composition ${ }^{\mathrm{a}}$ of orange flavoured Aloe vera gel.

\begin{tabular}{cccccccc}
\hline S. No. & $\begin{array}{c}\text { Moisture, } \\
\%\end{array}$ & Ash, $\%$ & $\begin{array}{c}\text { Protein, } \\
\%\end{array}$ & $\begin{array}{c}\text { Crude } \\
\text { Fibre, } \%\end{array}$ & $\begin{array}{c}\text { Carbohydrat } \\
\mathrm{e}, \%\end{array}$ & $\mathrm{pH}$ & $\mathrm{TSS},{ }^{0} \mathrm{~B}$ \\
\hline Aloe vera & & & & & & & \\
gel & $\begin{array}{c}76.33 \pm \\
0.52\end{array}$ & $\begin{array}{c}1.29 \pm \\
0.04\end{array}$ & $\begin{array}{c}4.03 \pm \\
0.06\end{array}$ & $\begin{array}{c}2.50 \pm \\
0.41\end{array}$ & $18.09 \pm 0.09$ & $\begin{array}{c}3.53 \pm \\
0.05\end{array}$ & $\begin{array}{c}41.77 \pm \\
0.73\end{array}$ \\
\hline
\end{tabular}

${ }^{a}$ Mean value \pm standard deviation $(\mathrm{n}=3)$.

Table 2: Sensory score ${ }^{\mathrm{a}}$ of orange flavoured gel.

\begin{tabular}{cccccccc}
\hline S. No. & Color & Texture & Aroma & Taste & Stickiness & $\begin{array}{c}\text { Overall } \\
\text { acceptability }\end{array}$ & Rank \\
\hline $\begin{array}{c}\text { Flavoured } \\
\text { Gel }\end{array}$ & $8.10 \pm 0.54$ & $7.8 \pm 0.60$ & $8.10 \pm 0.54$ & $8.10 \pm 0.30$ & $7.8 \pm 0.60$ & $8.00 \pm 0.45$ & $8.10 \pm 30$ \\
\hline${ }^{a}$ Mean value & stand & & & & \\
\end{tabular}

${ }^{\mathrm{a}}$ Mean value \pm standard deviation $(\mathrm{n}=10)$.

\section{Conclusion}

A novel orange flavoured Aloe vera gel was successfully produced with unique sensory attributes like attractive color, sweet taste, and good consistency and non-sticky. Citric acid improved the stability of the gel against browning. Besides imparting sweet taste, sugar also improved the texture of the gel. From the nutritional and sensory characteristics gel when augmented with $1.5 \%$ pectin, $9 \%$ gum acacia and $15 \mathrm{~g}$ orange flavour resulted in better quality gel with smooth texture, acceptable appearance and aroma and attractive colour and good nutritional value (protein content $4 \%$, carbohydrate content $18.6 \%$, TSS $41.7{ }^{\circ} \mathrm{B}$, fibre content $2.83 \%$ and mineral content $1.29 \%$ ). 


\section{References}

[1]

rabbit, J. Biosci., Vol. 10.251-256.

Galal Z, Nazek Abdul-Kariem Mahmoud (2001) Human Parvovirus B19 Infection: its role in acute arthropathies, Vol. 28 , no. 4

[6] Imanishi, K., Ishigura, T., Saito, H. andSuzuki, I. 1981. Pharmacological studieson plant lectin, Aloctin A.I. Growth inhibition of mouse methlcholanthreneinducedfibrosarcoma (Meth. A). Inascites form by Aloctina. Experientia, 37:1186-1187.

[7] King GK, Yates KM, Greenlee PG (1995). The effect of acemannanimmunostimulantin combination with surgery and radiation therapy on spontaneous canine and feline fibrosarcomas. J.of the Animal Hospital Assoc. 31: 439-447.

[8] L. Ralamboranto et al., Immunomodulating Properties of an Extract Isolated and Partially Purified from Aloe Vahombe, Archives de 1 Institut Pasteur de Madagascar 50(1):227-56 (1982).

[9] QianHea, Liu Changhong (2005) Quality and safety assurance in the processing of aloe vera gel juice. Elsevier, Volume 16, Issue 2, February 2005, Pages 95-104.

[10] Sai Lakshmi, LSS Abirami, Pushkala (2011) Enhancement of storage life and quality maintainence of papaya fruits using aloe vera based antimicrobial coationg, Indian Jour of Biotech. Vol 10, 83-89.

[11] Thomson PDR (2004). Herbal Medicines, Third Edition, NJ: Thomson PDR. 16-20.

[12] ZhanHai Yu, Che Jin, Ma Xin, He JianMin (2009) Effect of Aloe vera polysaccharides on immunity and antioxidant activities in oral ulcer animal models. Elsevier, Volume 75, Issue 2, 22 January 2009, Pages 307-311. 